\title{
Impact of Janani Suraksha Yojana on institutional delivery in Empowered Action Group States, India
}

\author{
Lopamudra Paul ${ }^{1}$, Ramesh Chellan ${ }^{2}$
}

\author{
${ }^{1}$ Monitoring and Evaluation Specialist, FHI 360, New Delhi, India. ${ }^{2}$ Results and Evidence Expert, Odisha Technical and \\ Management Support Team, Bhubaneswar, Odisha, India.
}

\begin{abstract}
The National Population Policy (NPP) in India defined goal to increased institutional delivery and reducing Maternal Mortality Ratio (MMR). Therefore, National Rural Health Mission (NRHM) aimed to increased expenditure to provide primary health care services to poor households in rural India through Janani Surakshya Yojana (JSY), which provide referral transport, escort and improved hospital care for institutional deliveries. The study concludes from District Level Household Surveys (DLHS)-2 and 3 data that Janani Surakshya Yojana undoubtedly contributed to a tremendous improvement in institutional delivery. Accredited Social Health Activist (ASHA), found as an effective link between the Government and the poor pregnant women to provide information on Janani Surakshya Yojana. States like Madhya Pradesh, Odisha and Rajasthan have an impressive rise in institutional delivery and also high percentage of women received financial benefits through the JSY. Planned implementation of programme through NRHM may help achieve the goals of NPP 2000 and hence Millennium Development Goal (MDG)-5 to save life of millions mothers and newborn in India.
\end{abstract}

Keywords: Janani Surakshya Yojana, Institutional delivery, ASHA, Socio-economic, India.

\section{Introduction}

In 2000, as part of the Millennium Development Goals (MDGs), the international community committed to decrease the Maternal Mortality Ratio (MMR) by $75 \%$ by 2015 and improve overall maternal health care to achieve MDG-5. India has one of the highest MMR in the world with an estimated 212 maternal deaths per 100,000 live births. ${ }^{2}$ Most of deliveries in India occurs at home and without any assistance from skilled health professionals and hence majority of the maternal deaths contributed by the mothers who had a home delivery. ${ }^{3-4}$ Therefore, Indian government introduced the National Population Policy (NPP) 2000 with defined goal to increased institutional delivery by $80 \%$, safe delivery by $100 \%$ and reducing MMR by 100 per 100,000 live births. ${ }^{5}$

In order to achieve these goals, the National Rural Health Mission (NRHM) was launched in 2005, which aimed to undertake an 'architectural correction' of the public health system to enable it to effectively absorb increased expenditure to provide accessible, affordable and accountable in primary health care services to poor households in remote parts of rural India. ${ }^{6-8}$ The expected outcome of the mission is to make availability of trained community level worker at village level with a generic drug kit. This means 'People's Health in People's Hand' with more of community participation and community monitoring of public health system. The NRHM implemented the Janani Surakshya Yojana (JSY) for the Below Poverty Line (BPL) families which provide referral transport, escort and improved hospital care at subsidized rate for institutional deliveries. ${ }^{6-8}$ The Janani Surakshya Yojana was launched by the Hon'ble Prime Minister on

\section{Practice Points}

- Janani Surakshya Yojana (JSY) under NRHM provides referral transport, escort and improved hospital care for institutional deliveries to poor households in rural India

- There is substantial increase in institutional delivery from 2002-04 (DLHS-2) to 2007-08 (DLHS-3) in all EAG states in India.

- JSY has significant impact on institutional delivery, however the impact is not same across all EAG states in India

- ASHA workers are found to be catalyst in the change in behaviour among rural people on increased institutional delivery.

- Financial benefits supposed to be a great motivation factor but did not succeed in some states to motivate on institutional delivery due to poor transportation system to bring women for delivery at health facility.

$12^{\text {th }}$ April, 2005 and being implemented in all states and union territories with special focus on Low Performing States (LPS). The JSY provides benefits for delivery and post-delivery care and it is fully centrally sponsored scheme. ${ }^{8}$ Success of the scheme is determined by the increase in institutional delivery among the poor families. The scheme has identified Accredited Social Health Activist (ASHA), as an effective link between the Government and the poor

Correspondence: Dr. Lopamudra Paul, Monitoring and Evaluation Specialist, Family Health International (FHI 360), New Delhi, India. Email: lopamudra77@gmail.com. 
pregnant women in ten low performing states, namely the eight Empowered Action Group (EAG) states (Bihar, Chhattisgarh, Jharkhand, Madhya Pradesh, Odisha, Rajasthan, Uttrakhand and Uttar Pradesh), Assam, Jammu and Kashmir and the remaining Northeastern states. ${ }^{8}$ In rest of the states, Anganwadi Workers (AWW) and Trained Birth Attendants (TBA) or ASHA like activists have been engaged with JSY for providing the services. The target group under JSY includes all pregnant women (19 years and above in age, up to two live births) belonging to the below poverty line. In the ten low performing states, the benefit would extend even after the third live births if the mother, of her own accord chooses to undergo sterilization in the health facility where she delivered, immediately after the delivery (Table 1).

The Janani Surakshya Yojana has brought together poorly functional maternity-nutrition benefit scheme and referral transport scheme into a single package and by focusing this package on institutional delivery. ${ }^{6-8}$ The financial benefits were earlier only for institutional deliveries but soon after Rs. 500 benefit for home delivery for BPL family was introduced to retain the maternity benefit component. However, the scheme in practice is almost completely focused on promotion of

Table 1: Criteria to Avail the JSY Benefits ${ }^{8}$ institutional delivery the payments for home delivery are low and not encouraged. Informally they could be actively discouraged (Table 2).

Although the Janani Surakshya Yojana was aimed to increase institutional delivery and reduced maternal and neo-natal deaths but it poses a serious discussion that how far this cash incentive changes the behavior of the community discussion in favor of institutional delivery? The rationale is that beneficiary would be able to use the JSY benefits for her care during delivery or to meet incidental expenses of delivery. It should be the responsibility of Auxiliary Nurse Midwife (ANM)/ ASHA, medical officer in primary health centre to ensure disbursement. It is very important that the cash is disbursed in time to help the beneficiary to get the maximum benefits of the scheme.

Studies in last few years tried to focus on the acceptability and utilization of the scheme and its effect on improving utilization of public health care system especially in rural India. An overall estimate from District Level Household Surveys (DLHS-2 and 3) data show that the poorest and least educated women did not always have the highest odds of receiving JSY payments. ${ }^{3-4}$ Janani Surakshya Yojana had a significant

\begin{tabular}{|c|c|c|}
\hline $\begin{array}{l}\text { Low Performing } \\
\text { States (LPS) }\end{array}$ & • & $\begin{array}{l}\text { All pregnant women delivering in Government health centres like health sub-centre } \\
\text { (specifically approved for institutional delivery by State), Primary Health Centre (PHC)/ } \\
\text { Community Health Centre (CHC)/First Referral Units (FRU)/General wards of district } \\
\text { and state hospitals. } \\
\text { Below poverty line and Scheduled Caste (SC) and Scheduled Tribe (ST) women deliver- } \\
\text { ing in accredited private institutions. } \\
\text { Restriction of JSY benefit up to two live births removed (No restriction of no. of births). } \\
\text { Restriction of age of } 19 \text { years and above removed (No restriction of age). }\end{array}$ \\
\hline $\begin{array}{l}\text { High Performing } \\
\text { States (HPS) and } \\
\text { North-Eastern } \\
\text { States (Except } \\
\text { Assam) }\end{array}$ & $\bullet$ & $\begin{array}{l}\text { BPL pregnant women, aged } 19 \text { years and above delivering in Government health centres } \\
\text { like health sub-centre (specifically approved for institutional delivery by state), PHC/ } \\
\text { CHC/FRU/General wards of district and state hospitals or accredited private institutions. } \\
\text { All SC and ST women delivering in a government health centre like health sub-centre } \\
\text { (approved for institutional delivery by state), PHC/CHC/FRU/General ward of district } \\
\text { and state hospitals or accredited private institutions. } \\
\text { For SC/ST women, age restriction of } 19 \text { year is not applicable. } \\
\text { Cash assistance for institutional delivery would be limited to two live births for all the } \\
\text { women. }\end{array}$ \\
\hline
\end{tabular}

Table 2: Financial Benefits under JSY for Mother and $\mathrm{ASHA}^{8}$

\begin{tabular}{|l|c|c|c|c|c|c|}
\hline \multirow{2}{*}{ Category } & \multicolumn{3}{|c|}{ Rural Area (in Rs.) } & \multicolumn{3}{c|}{ Urban Area (in Rs.) } \\
\cline { 2 - 7 } & $\begin{array}{l}\text { Mother's } \\
\text { Package }\end{array}$ & $\begin{array}{l}\text { ASHA's } \\
\text { Package }\end{array}$ & Total & $\begin{array}{l}\text { Mother's } \\
\text { Package }\end{array}$ & $\begin{array}{l}\text { ASHA's } \\
\text { Package }\end{array}$ & Total \\
\hline Low performance states & 1,400 & 600 & 2,000 & 1,000 & 200 & 1,200 \\
\hline $\begin{array}{l}\text { North-Eastern states (except Assam) and } \\
\text { Rural areas of tribal districts of HPS } \\
\text { States }\end{array}$ & 700 & 600 & 1,300 & 600 & 200 & 800 \\
\hline High performance states & 700 & Nil & 700 & 600 & Nil & 600 \\
\hline
\end{tabular}


effect on increasing antenatal care and in-facility births. ${ }^{9}$ Another study among 100 beneficiaries in selected villages in Bikaner district in Rajasthan shows that major advantages of the Janani Surakshya Yojana were perceived by the beneficiaries such as safe delivery at PHCs and CHCs, payment of cheque after delivery and full protection after delivery. ${ }^{10}$ A study among 400 currently married women aged 15-35 years living in rural areas of Seraikela-Kharsawan districts in West Singhbhum in Jharkhand on knowledge and awareness of Janani Surakshya Yojana revealed that $83 \%$ of the respondents have heard about the JSY and also know someone who had received its benefits but $54 \%$ did not know the types of benefits and $18 \%$ knew that if delivery is done in a hospital they will get Rs. 1,650. The respondents also reported that they have knowledge that Saahiya (ASHA) gets financial benefits for accompanying mother for institutional delivery and post natal care. About three-fifths of women stated that they came to know about JSY from ANM. ${ }^{11}$

A study conducted in rural Odisha to estimate the impact of JSY scheme. Six blocks from three districts were selected for the study and data were collected from both beneficiary and non-beneficiary mothers and other stakeholders of the Janani Surakhya scheme. ${ }^{12}$ The study found that less than half of both beneficiaries as well non-beneficiary mothers knew about the various aspects of the JSY scheme. Three-fourths of the beneficiaries reported to first contact with ASHA for ANC in between the third and sixth month of the pregnancy. Most of the respondents feel that there are problems of communication and transport.

The ASHAs also played a major role in motivation for institutional deliveries in two-thirds of the beneficiaries but lack of orientation of the health staffs other than ASHAs on JSY is a significant finding emerging from this study. It is found that there is a gap in utilization of JSY may be contributed by many unforeseen factors. The main aim of the scheme is to increase the institutional delivery and hence reduce maternal deaths to achieve the MDG-5. Therefore, to understand the effect of JSY on institutional delivery and the utilization of the scheme across the various socio-economic sections in the society, the present study has focused on the impact of utilization of JSY in the eight EAG states in India. The impact here denoted as increase in institutional delivery per se.

The major objectives of the paper are as follows:

- To assess the change in institutional delivery in between 2002-04 and 2007-08.

- To examine the influence of socio-economicdemographic and programme factors on the change in utilisation of institutional delivery in the Empowered Action Group states over time.

- To investigate the whether there are any impacts of Accredited Social Health Activist workers and cash incentives on change in percentage of institutional deliveries in the Empowered Action Group states.

\section{Materials and Methods}

Data on institutional delivery is available in the three round of National Family Health Surveys (1992-93, 1998-99, and 2005-06) and also from the three rounds of District Level Household Surveys, (1998-99, 200204, and 2007-08) in India. ${ }^{3-4,13-16}$ Data of utilization of JSY was collected during District Level Household and Facility Survey (DLHS-3) and hence to determine the reach and utilization of services under the Janani Surakshya Yojana scheme in EAG states, data from DLHS-3, 2007-08 was used. ${ }^{3}$ The survey provides data on institutional delivery, deliveries facilitated by ASHAs, institutional deliveries by trained birth attendants, and utilization of the JSY scheme by women belonging to different socio-economic and demographic backgrounds. To analyze the change in the utilization of institutional delivery before and after implementation of Janani Surakshya Yojana data from two different time points were required. The DLHS-2, 2002-04 was conducted nationwide before initiation of NRHM and implementation of JSY in 2005. Therefore, to compare the change which may affect the utilization of institutional delivery after initiation of the scheme data from DLHS-2 was used. Finally, to understand the net effect attributed by JSY which data was collected during DLHS-3, and hence comparison between DLHS-2 and DLHS-3 rounds are made. A cross-sectional study on utilization of JSY scheme and institutional delivery was carried out from the individual data of 116,268 among currently married women from DLHS-3 who had their last live/still birth in the last three years prior to the DLHS-3 survey. Similar analysis was also carried out from DLHS-2 data among 104,452 women living in the EAG states.

Primarily the paper seeks the change in behaviour on utilization of Janani Surakshya Yojana and institutional delivery across EAG states and the region as a whole. First, the gross differentials in institutional delivery by selected socio-economic and demographic factors are obtained and examined through bivariate analysis for DLHS-2 and DLHS-3. This analysis depicts the change in the behavior and level of utilization of institutional delivery across the socio-economic classes before and after implementation of JSY. Key variable of JSY, 'whether motivated by ASHA for institutional delivery', is used in DLHS-3. It is well discussed that socioeconomic variables are interrelated to each other and hence to examine the net effect of an individual variable, multivariate analysis was carried out employing the binary logistic regression model, since the response variable, utilisation of institutional delivery is dichotomous and predictor variables are in categorized form (for details see Retherford and Choe, 1993). ${ }^{17}$ Standard of living was calculated in DLHS-2 but in DLHS-3 wealth index was computed to show the economic condition of the households. To make the comparison uniform between both the surveys, type of houses is used as a proxy for the standard of living in the study.

In addition, the paper also analyzed the data on people 
who have received financial benefits from JSY in EAG states. Motivation for institutional delivery by ASHA is an important factor as NRHM promotes these health care functionaries at grass root level to help the community to avail the services and also increase awareness on the free services available. Therefore, separate analysis with socio-economic factors of motivation by ASHA on institutional delivery was done to understand whether all section of the community gets the said facility or not. Transportation plays an important role on institutional delivery. In rural areas inaccessibility to health facility influenced more on home delivery. Therefore, role of transportation to health facility for delivery is important and JSY provides financial assistance on transportation for institutional delivery.

\section{Results and Discussion}

The results show that overall institutional delivery has increase from $22.9 \%$ in DLHS-2 to $33.4 \%$ during DLHS -3 in EAG states in India (Figure 3). This is a substantial increase in institutional a small period of time. However, there is variation increase in institutional births across the EAG states. The increase in institutional births is the highest in Madhya Pradesh (27.7\% in DLHS-2 and 50\% in DLHS-3) and the lowest in Jharkhand between both surveys (19.5\%: DLHS-2 and 20.2\%: DLHS-3). Rajasthan had the highest percentage of institutional delivery among EAG states during DLHS-2 survey but replaced with Madhya Pradesh through great improvement in institutional delivery in last few years. Chhattisgarh was the poorest performing state in terms of institutional delivery in 2002-04 and Jharkhand become the worst performing in 2007-08 with almost no improvement in the situation. This may have influenced by socio-economic and demographic factors along with program factors, which is discussed later in this paper. Other indicators like percentage of women registered in first trimester when pregnant with last live/still birth and had at least three ANC during last pregnancy have improved between both surveys in all EAG states (Figures 1 and 2). Remarkable improvement occurred in gateway behaviour like early registration of pregnancy which indicates a positive change in community behaviour towards safe pregnancy. It is well established that there is a positive relation on full ANC and hen increased institutional delivery with early registration of pregnancy.

Although, overall percentage of women motivated for ANC and institutional delivery by ASHA is still low in all EAG states but certainly it is a notable movement in community participation (Figure 6). ASHA, who are introduced as catalyst to improve healthy behaviour in the rural community must have initiated the process and in such a short time some improvement has been noticed. Institutional delivery increased during this period; on the other hand, home delivery assisted by skilled health personal has declined marginally (Figure 4). However, still way to go to achieved goal for $100 \%$ safe delivery as stated in the NPP in these states. It is evident the stir on institutional delivery has been creased.
JSY was meant to increase institutional delivery by motivating women through financial assistance and support by ASHA on referral and transportation. However, DLHS-3 data indicates that only $10.6 \%$ women received the financial assistance for delivery through JSY in all EAG states (Figure 5). The figure is the highest in Madhya Pradesh and the lowest in Jharkhand easily emphasized the fact that the key for low motivation for the institutional delivery in Jharkhand.

Low percentage receiving financial assistance may dampen the motivation to utilize the health facilities offered by the NRHM but it is also true that rural population is aware of the benefits and in coming days they will fully utilize the benefits. It is important to note that overall home delivery in these EAG states has declined from $76.7 \%$ during DLHS-2 to $65.8 \%$ (Table 3 ). However, the contribution of private healthcare facilities in increased institutional delivery is marginal during this period. This is because may be the cost in the private facilities or not all private facilities are accredited by Govt.

There may be another factor influence beneficiaried to choose Govt. health facilities over a private one is the reform in the health sector in rural area through NRHM. This is clearly reflected in substantial increase in percentage of deliveries in $\mathrm{PHC}$ and $\mathrm{CHC} /$ Rural hospital from DLHS-2 to DLHS-3. Percentage of delivery at Government hospital has increase between two surveys in Odisha, Madhya Pradesh, Uttarakhand, and Rajasthan among eight EAG states. Simultaneously, delivery at $\mathrm{PHC}, \mathrm{CHC} /$ Rural hospitals also increased in many folds in these states. Although there is marginal increase in percentage of delivery at private hospital and clinics in Uttar Pradesh, Bihar, Chhattisgarh, and Jharkhand but utilisation of public health facility for delivery remain minimal in these states during this period. This may indicates the apathy on utilization of the public health care among community in these states. There is clear variation in state level in utilization of public health facilities for delivery. The aim of JSY to mobilize community to utilize public health care and encourage public-private partnership to a healthy family and hence a healthy society, is yet to achieve in these states.

There are many studies emphasized on effect of socioeconomic and programme factors on utilisation of institutional delivery. ${ }^{18-24}$ The present paper also seeks the changing pattern of behaviour across the socioeconomic classes on institutional delivery in EAG states. EAG states are defined as with high fertility rates and weak on socio-economic indicators by Ministry of Health and family Welfare in India. The EAG was created to ensure population stabilisation and intersectoral convergence. Table 4 reveals that changing pattern of behaviour within the socio-economic variables on institutional delivery. The rural-urban gap has narrowed from DLHS-2 to DLHS-3. Percentage of women had institutional delivery has increase among Hindu and Muslims but declined among others religions (Christians, Buddhists, Jain etc.). It is well established 
Figure 1: Percentage of women registered in the first trimester of their pregnancy

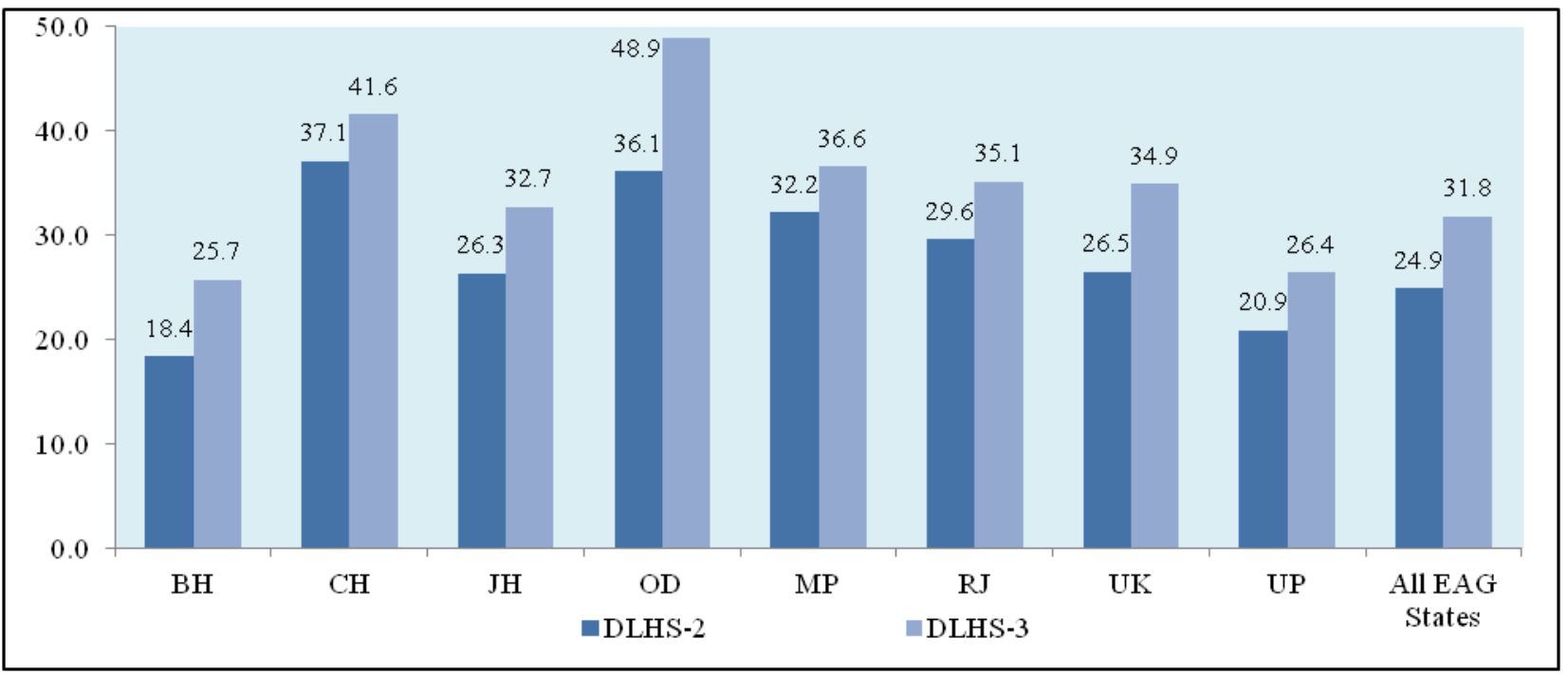

Figure 2: Percentage of women had at least three antenatal care check-ups during pregnancy

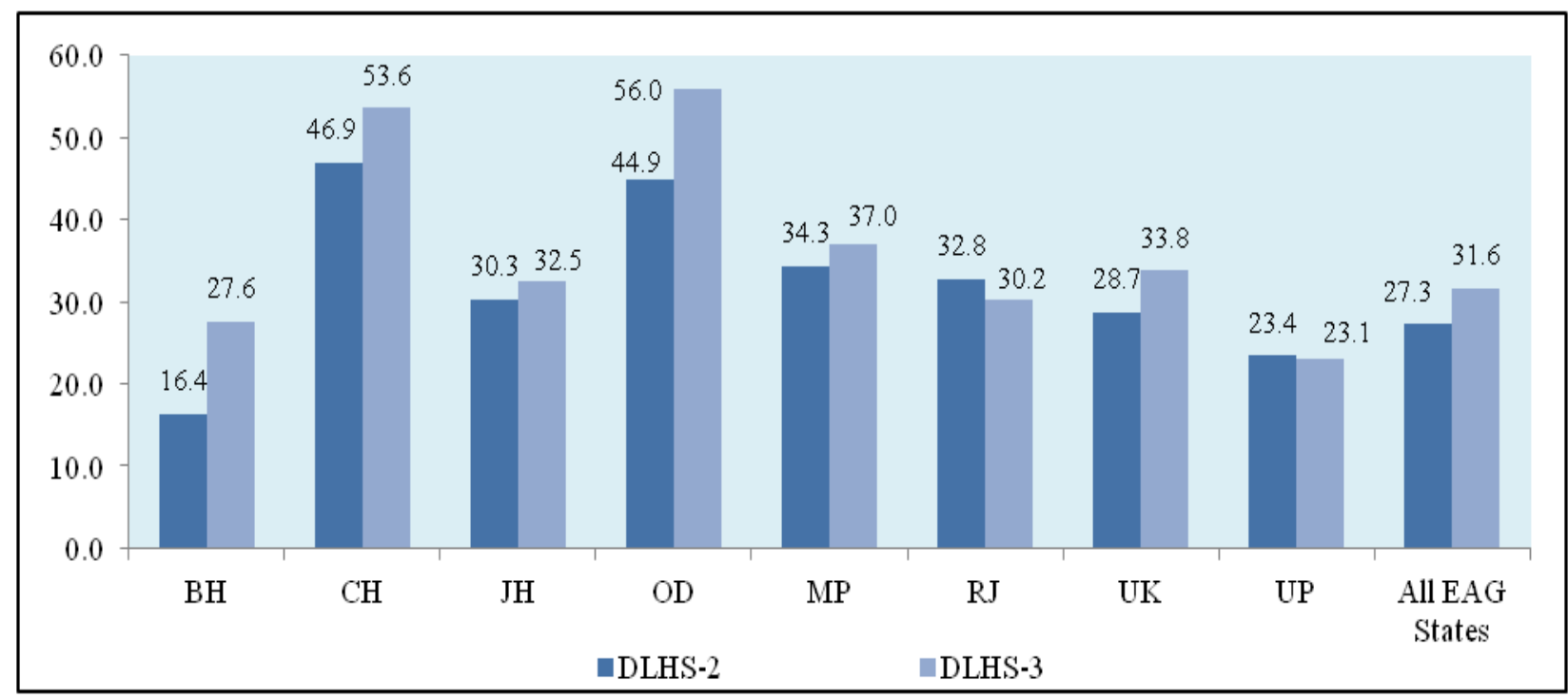

Figure 3: Percentage of women had institutional delivery

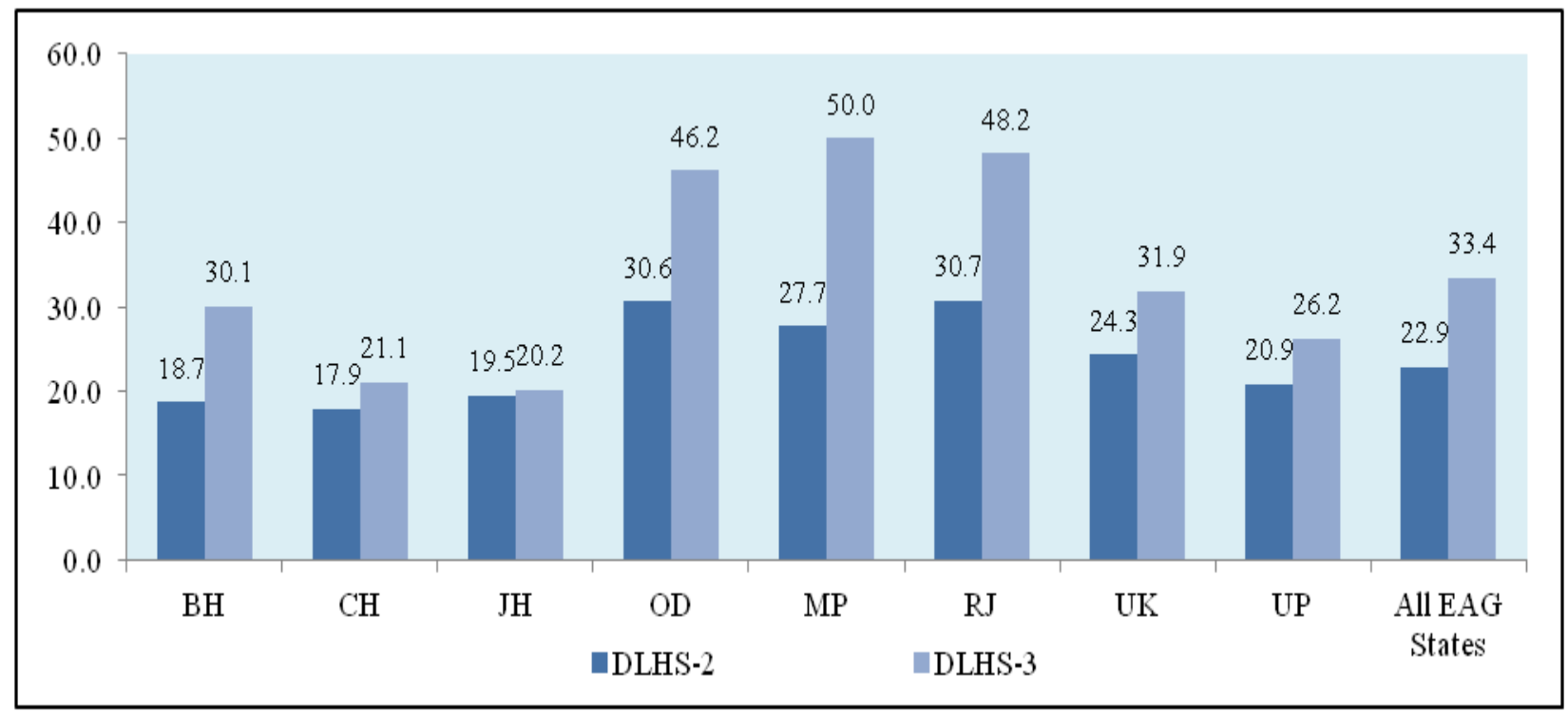

Note: BH: Bihar; CH: Chhattisgarh; JH: Jharkhand; MP: Madhya Pradesh; OD: Odisha; RJ: Rajasthan; UK: Uttarakhand; UP: Uttar Pradesh. 
Figure 4: Percentage of women had home delivery assisted by skilled health personnel

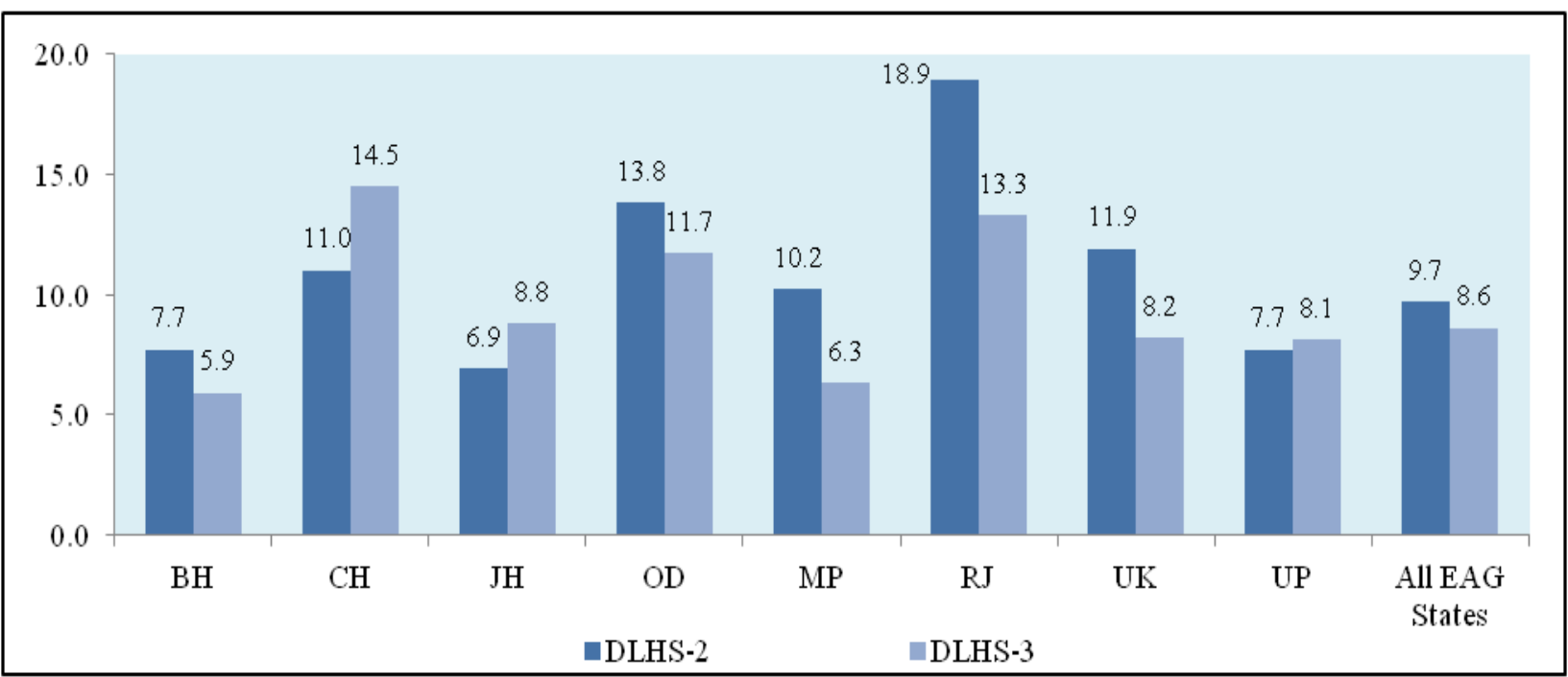

Figure 5: Percentage of women received financial assistance for delivery under JSY

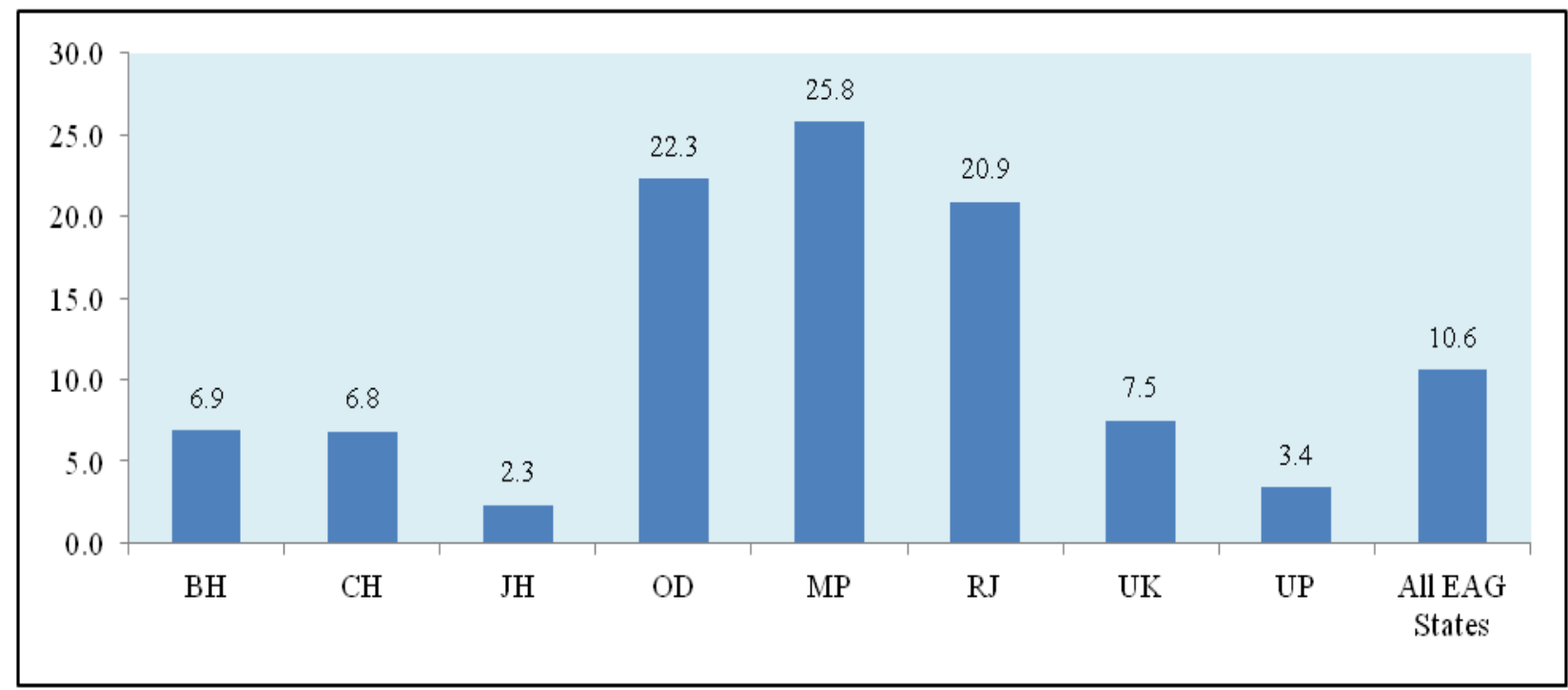

Figure 6: Percentage of women facilitated and motivated by ASHA for antenatal care and delivery at health facility

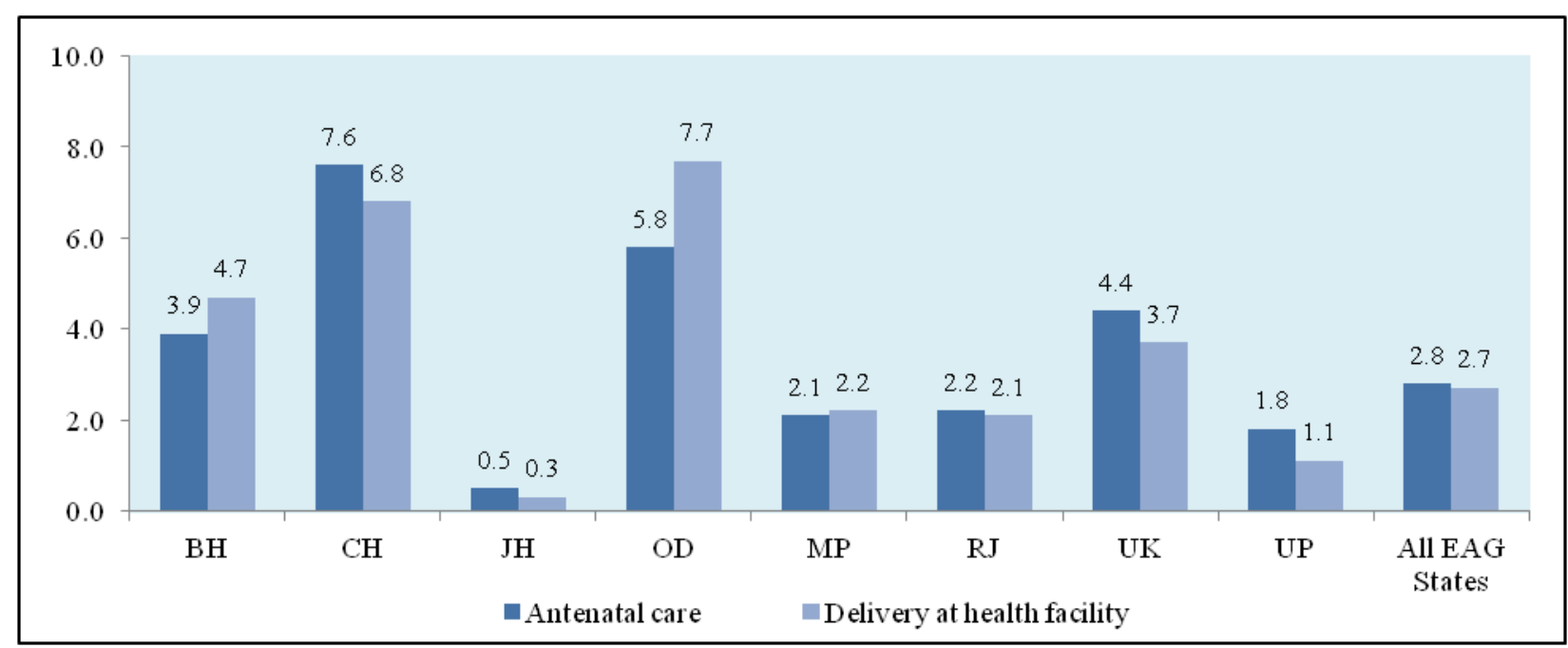

Note: BH: Bihar; CH: Chhattisgarh; JH: Jharkhand; MP: Madhya Pradesh; OD: Odisha; RJ: Rajasthan; UK: Uttarakhand; UP: Uttar Pradesh. 
Table 3: Percentage distribution of place of delivery in EAG states of India

\begin{tabular}{|c|c|c|c|c|c|c|c|c|c|}
\hline Place of Delivery & BH & $\mathbf{C H}$ & JH & MP & OD & RJ & UK & $\mathbf{U P}$ & $\begin{array}{c}\text { All EAG } \\
\text { States }\end{array}$ \\
\hline \multicolumn{10}{|c|}{ DLHS-2 } \\
\hline Government/Municipal Hospital & 3.2 & 5.2 & 3.8 & 11.8 & 13.2 & 9.6 & 9.2 & 5.0 & 6.6 \\
\hline Government Dispensary & 0.8 & 2.8 & 0.2 & 2.2 & 1.5 & 3.7 & 0.7 & 0.7 & 1.4 \\
\hline UHC/UHP/UFWC & 0.1 & 0.0 & 0.0 & 0.1 & 0.3 & 0.4 & 0.0 & 0.1 & 0.1 \\
\hline CHC/Rural hospital & 0.1 & 0.1 & 0.1 & 1.5 & 3.4 & 2.1 & 0.2 & 0.5 & 0.9 \\
\hline PHC & 0.4 & 0.4 & 0.5 & 1.4 & 4.5 & 2.6 & 0.5 & 1.4 & 1.4 \\
\hline Sub center & 0.1 & 0.2 & 0.0 & 0.3 & 0.4 & 0.5 & 0.1 & 0.4 & 0.3 \\
\hline NGO/Trust hospital & 0.1 & 0.3 & 0.6 & 0.1 & 0.2 & 0.0 & 0.4 & 0.2 & 0.2 \\
\hline Government ISM hospital/clinic & 0.1 & 0.2 & 0.1 & 0.1 & 0.2 & 0.1 & 0.2 & 0.1 & 0.1 \\
\hline Private ISM hospital/clinic & 0.2 & 0.3 & 0.4 & 0.3 & 0.5 & 0.4 & 1.7 & 0.7 & 0.5 \\
\hline Private Hospital/Clinic & 13.9 & 8.4 & 13.8 & 9.9 & 6.4 & 11.3 & 11.2 & 11.8 & 11.6 \\
\hline Home & 81.0 & 82.0 & 80.2 & 72.0 & 68.3 & 68.8 & 75.6 & 78.6 & 76.7 \\
\hline Others & 0.2 & 0.7 & 0.3 & 0.3 & 1.0 & 0.5 & 0.1 & 0.4 & 0.3 \\
\hline Number of women & 18,311 & 5,361 & 7,442 & 15,926 & 9,188 & 13,509 & 3,710 & 31,005 & 104,452 \\
\hline \multicolumn{10}{|c|}{ DLHS-3 } \\
\hline Government Hospital & 5.9 & 6.2 & 4.2 & 17.9 & 20.1 & 13.6 & 12.1 & 3.8 & 8.8 \\
\hline Government Dispensary & 0.1 & 0.0 & 0.0 & 0.1 & 0.3 & 0.3 & 0.0 & 0.1 & 0.1 \\
\hline UHC/UHPC/UFWC & 0.1 & 0.1 & 0.1 & 0.3 & 0.6 & 0.3 & 0.2 & 0.1 & 0.2 \\
\hline CHC/Rural hospital & 0.6 & 2.8 & 0.1 & 13.4 & 7.5 & 13.0 & 2.3 & 2.0 & 4.9 \\
\hline PHC & 6.1 & 1.8 & 1.2 & 7.5 & 8.8 & 8.7 & 4.4 & 2.8 & 5.0 \\
\hline Sub center & 0.4 & 0.7 & 0.2 & 0.8 & 0.4 & 0.9 & 0.3 & 0.8 & 0.6 \\
\hline AYUSH hospital/clinic & 0.1 & 0.0 & 0.0 & 0.0 & 0.1 & 0.0 & 0.0 & 0.0 & 0.0 \\
\hline NGO/Trust/Clinic & 0.2 & 0.2 & 0.1 & 0.2 & 0.2 & 0.2 & 0.2 & 0.4 & 0.2 \\
\hline Private Hospital/Clinic & 16.5 & 9.1 & 13.4 & 9.7 & 8.0 & 11.2 & 11.8 & 15.9 & 13.3 \\
\hline Private AYUSH Hospital/Clinic & 0.2 & 0.1 & 0.4 & 0.2 & 0.3 & 0.2 & 0.4 & 0.3 & 0.3 \\
\hline Home & 69.1 & 78.6 & 79.4 & 49.3 & 52.6 & 51.0 & 67.6 & 72.9 & 65.8 \\
\hline Others & 0.9 & 0.3 & 0.5 & 0.7 & 1.1 & 0.7 & 0.4 & 0.9 & 0.8 \\
\hline Number of women & 21,315 & 6,114 & 11,298 & 15,839 & 7,637 & 12,405 & 4,097 & 37,563 & 116,268 \\
\hline
\end{tabular}

Source: computed from DLHS-2, 2002-04 and DLHS-3, 2007-08 data files .

Note: 1. BH: Bihar; CH: Chhattisgarh; JH: Jharkhand; MP: Madhya Pradesh; OD: Odisha; RJ: Rajasthan; UK: Uttarakhand; UP: Uttar Pradesh; UHC: Urban Health Centre; UHP: Urban Health Post; UFWC: Urban Family Welfare Centre; CHC: Community Health Centre; ISM: Indian System of Medicine; NGO: Non Governmental Organisation. 2. Those currently married women in the age group of 15-44 years who experienced live or still births during three years preceding the survey. 3 . The percentages are computed after applying survey sample weights and the number of women given in unweighted.

in literature on public health that marginalised groups are not reached by health system and the utilisation of health facilities are very poor among these groups. As the JSY scheme focused on to mainstreaming the marginalised group like Scheduled Caste, Scheduled Tribe and Other Backward Castes (OBCs) in the society to access the institutional delivery services, the results show an increase in percentage of women who had utilised institutional delivery from DLHS-2 to DLHS-3 in these groups of people. This provides a bright picture for the scheme's success. Percentage of women having institutional delivery increases with rise in level of education. Although, the pattern in utilisation of institutional delivery remains the same from round two to round three of DLHS across the educational categories but the there is substantial in utilisation of institutional delivery among illiterate women and women with primary education during DLHS-3. This provides the effect of the JSY scheme where women with none/low education also motivated to deliver their baby at health facilities. However, the gap across the economic classes (types of house considered as proxy) did not change on utilisation of institutional delivery between two surveys, only the level has increased over time. Similar scenario found for women with different age groups, age at marriage and with number of ANC visits. It is necessary to highlight that percentage of women has increased substantially with lower birth order (one and two) to delivery at health facilities during DLHS-3 compared to
DLHS-2, whereas it is marginally increased for higher birth orders. ASHA workers are the catalyst on utilisation of JSY scheme and 54.5\%women had reported that they were motivated by ASHA to have institutional delivery among who have institutional delivery. This provides that community participation in health system is flourishing in rural India.

The logistic regressions results also convey the same massage that pattern of utilisation of institutional delivery did not change across the socio-economic categories per se expect few isolated cases (Table 4) at two different time points (DLHS-2 and DLHS-3). It shows that women belong to OBC community are less likely to have institutional delivery compared to women belong to non-SC/ST/OBC community during DLHS-3, whereas the situation was reversed during DLHS-2. Similarly, DLHS-3 estimates shows that likelihood of having institutional delivery is low among Muslim women compared to Hindus while opposite scenario was prevailed during DLHS-2 survey. Women with two children are significantly less likely to utilise facility for institutional delivery than women with one child, however, it was not significant during DLHS-2. As expected, rise in education and standard of living has significantly positive impact on utilisation institutional delivery. Motivation to have an institutional delivery by ASHA is highly significant after controlling for all other variables. It clearly reveals that JSY scheme and 
Table 4: Prevalence of institutional delivery by selected background characteristics in EAG states of India

\begin{tabular}{|c|c|c|c|c|c|c|}
\hline \multirow{2}{*}{$\begin{array}{l}\text { Background } \\
\text { characteristics }\end{array}$} & \multicolumn{3}{|c|}{ DLHS-2 } & \multicolumn{3}{|c|}{ DLHS-3 } \\
\hline & $\begin{array}{c}\text { Percent had } \\
\text { institutional } \\
\text { delivery }\end{array}$ & $\begin{array}{l}\text { Odds } \\
\text { ratio }\end{array}$ & $\begin{array}{c}\text { Number of } \\
\text { women }\end{array}$ & $\begin{array}{c}\text { Percent had } \\
\text { institutional } \\
\text { delivery }\end{array}$ & $\begin{array}{c}\text { Odds } \\
\text { ratio }\end{array}$ & $\begin{array}{c}\text { Number } \\
\text { of women }\end{array}$ \\
\hline \multicolumn{7}{|l|}{ Residence } \\
\hline Rural & 16.8 & 1.000 & 77,928 & 27.1 & 1.000 & 100,339 \\
\hline Urban & 50.1 & $1.462 * *$ & 26,524 & 55.0 & $1.932 * *$ & 15,929 \\
\hline \multicolumn{7}{|l|}{ Religion } \\
\hline Hindu & 23.0 & 1.000 & 89,683 & 34.5 & 1.000 & 98,424 \\
\hline Muslim & 20.7 & $0.765^{* *}$ & 13,346 & 28.8 & $0.712 * *$ & 14,306 \\
\hline Others & 46.2 & $1.279 * *$ & 1,423 & 36.8 & $0.689 * *$ & 1,612 \\
\hline \multicolumn{7}{|l|}{ Ethnicity } \\
\hline Non SC/ST/OBC & 38.5 & 1.000 & 23,342 & 49.5 & 1.000 & 20,741 \\
\hline Scheduled Caste & 15.8 & $0.901 * *$ & 20,634 & 27.5 & $0.725 * *$ & 22,722 \\
\hline Scheduled Tribe & 12.4 & $0.744 * *$ & 11,973 & 21.1 & $0.645 * *$ & 16,364 \\
\hline Other backward castes & 21.5 & $1.096^{* *}$ & 48,503 & 32.7 & $0.802 * *$ & 56,212 \\
\hline \multicolumn{7}{|c|}{ Educational level (Years of Schooling) } \\
\hline Illiterate/ No schooling & 13.3 & 1.000 & 65,566 & 21.3 & 1.000 & 68,565 \\
\hline $0-5$ & 24.1 & $0.753 * *$ & 11,440 & 33.2 & $1.221 * *$ & 16,380 \\
\hline $6-10$ & 40.3 & $1.047 * *$ & 19,412 & 49.2 & $1.627 * *$ & 23,464 \\
\hline $11+$ & 73.4 & $2.090 * *$ & 7,952 & 76.2 & $2.732 * *$ & 7,826 \\
\hline \multicolumn{7}{|l|}{ Type of house } \\
\hline Kuchcha & 12.6 & 1.000 & 46,985 & 23.4 & 1.000 & 55,482 \\
\hline Semi-pucca & 21.2 & $0.971^{*}$ & 32,531 & 31.5 & $1.233 * *$ & 38,280 \\
\hline Pucca & 47.7 & $1.421 * *$ & 24,936 & 55.7 & $1.707 * *$ & 22,505 \\
\hline \multicolumn{7}{|l|}{ Age of women (in Years) } \\
\hline 15-19 & 22.9 & $0.897 * *$ & 9,889 & 37.1 & 0.977 & 7,896 \\
\hline $20-24$ & 25.3 & 1.000 & 36,142 & 38.5 & 1.000 & 39,515 \\
\hline $25-29$ & 24.4 & 0.998 & 31,656 & 34.0 & 1.002 & 37,400 \\
\hline $30-34$ & 19.4 & $1.075^{* *}$ & 17,082 & 27.9 & 1.033 & 19,911 \\
\hline $35+$ & 15.8 & $1.190^{* *}$ & 9,683 & 21.0 & 1.020 & 11,546 \\
\hline \multicolumn{7}{|l|}{ Age at marriage (in Years) } \\
\hline$<18$ & 15.8 & 1.000 & 66,176 & 25.5 & 1.000 & 70,638 \\
\hline$>18$ & 36.6 & $1.087 * *$ & 38,276 & 44.4 & $1.052 * *$ & 45,630 \\
\hline \multicolumn{7}{|l|}{ Children ever born } \\
\hline 1 & 38.0 & 1.000 & 24,173 & 51.1 & 1.000 & 27,741 \\
\hline 2 & 27.2 & 1.021 & 23,847 & 38.3 & $0.595 * *$ & 27,511 \\
\hline 3 & 19.7 & $0.818^{* *}$ & 18,889 & 26.3 & $0.457 * *$ & 36,186 \\
\hline $4+$ & 13.0 & $0.674 * *$ & 37,543 & 16.8 & $0.367 * *$ & 24,364 \\
\hline \multicolumn{7}{|l|}{ Pregnancy wastage } \\
\hline No & 22.3 & 1.000 & 88,881 & 33.1 & 1.000 & 98,888 \\
\hline Yes & 26.4 & $1.198 * *$ & 15,571 & 35.1 & $1.177 * *$ & 17,366 \\
\hline \multicolumn{7}{|l|}{ No. of ANC visits } \\
\hline No ANC visits & 9.2 & 1.000 & 41,753 & 15.8 & 1.000 & 42,705 \\
\hline 1 & 21.3 & $0.946^{*}$ & 11,415 & 32.7 & $2.081 * *$ & 8,677 \\
\hline 2 & 23.9 & $0.934 * *$ & 20,439 & 32.6 & $1.935 * *$ & 29,391 \\
\hline 3 & 29.4 & $1.113^{* *}$ & 12,763 & 40.0 & $2.370 * *$ & 19,264 \\
\hline $4+$ & 55.7 & $2.194 * *$ & 18,082 & 67.8 & $4.945 * *$ & 16,231 \\
\hline \multicolumn{7}{|l|}{ Motivated by ASHA } \\
\hline No & NA & NA & NA & 32.8 & 1.000 & 112,813 \\
\hline Yes & NA & NA & NA & 54.5 & $3.175 * *$ & 3,455 \\
\hline Constant & NA & 0.605 & NA & NA & 0.294 & NA \\
\hline-2 log likelihood & NA & $83,047.30$ & NA & NA & $116,326.57$ & NA \\
\hline Pseudo R square (Nagelkarke) & NA & 0.336 & NA & NA & 0.27 & NA \\
\hline Number of women & 22.9 & 104,370 & 104,452 & 33.4 & 113,606 & 116,268 \\
\hline
\end{tabular}

Source: computed from DLHS-2, 2002-04 and DLHS-3, 2007-08 data files.

Note: 1. NA: Not applicable. ${ }^{*} \mathrm{P}<0.05 ; * * \mathrm{p}<0.01$. 2. Those currently married women in the age group of $15-44$ years who experienced live or still births during three years preceding the survey. 3 . The percentages are computed after applying survey sample weights and the number of women given in unweighted. 4. For some of the factors, the numbers in categories may not add up to total due to missing information. 
motivation by ASHA has significant impact on increase of institutional delivery in EAG states. Community participation through the community member must have significant impact on increase in institutional delivery.

Table 5 provides the state level variation by socioeconomic and programme factors on prevalence of institutional delivery in EAG states. It reveals that level of institutional delivery has increased in all socioeconomic categories in all states from marginal to high. However, states like Jharkhand and Chhattisgarh improvement of utilisation of institutional delivery among illiterate are somewhat negligible. Madhya Pradesh and Rajasthan show sharp increase in institutional delivery among illiterate between DLHS-2 and 3. Similar scenario also found with types of houses in these states where women living in kachcha houses are accessing more institutional delivery during the recent survey compared to the earlier. ${ }^{9-10,24}$ This explains that the JSY scheme must have impact on changing behaviour of women in these states. Chhattisgarh and Rajasthan shows marginal difference in motivation of ASHA for institutional delivery whereas, states like Uttar Pradesh, Bihar, Odisha, Uttarakhand have major roles of ASHA on institutional delivery. Further, the bivariate results are second by the multivariate analysis to understand the net effect of certain variables. Rise in educational level have significantly positive impact on increase in utilisation of institutional delivery in almost all EAG states. But it is important to point out that women with primary level of education are significantly more likely to have institutional delivery compared to illiterate revealed from DLHS-3 survey.

On the other hand, education above primary level only had significantly positive influence on institutional delivery during DLHS-2. State like Madhya Pradesh and Rajasthan where increase in institutional delivery is high, low educational level does not play a significant role but types of house have positive impact on rise in institutional delivery in these states. Age of women, age at marriage, children ever born, ANC visits have significant influence on institutional delivery in all states and the pattern remained unchanged between both surveys. Motivation of ASHA workers on institutional delivery has significantly positive impact on institutional delivery in all states. This reveals that likelihood is high to have an institutional delivery if woman is motivated by ASHA. Therefore, the JSY encourage mothers to avail the monetary benefit to have an institutional delivery but to reach this massage to community, ASHA works as a catalyst within the community. To make the scheme more successful ASHA have a significant role to play.

JSY introduced financial benefits for the institutional delivery and to motivate rural poor's for institutional birth. This was introduced to lure more people to access and avail the health facility for delivery and hence reduced the maternal and neonatal deaths in rural areas. Table 7 clearly shows that very low percentage of people who had institutional delivery in states like Bi- har, Chhattisgarh, Jharkhand, Uttarakhand, Uttar Pradesh received the financial benefits. Madhya Pradesh, Odisha and Rajasthan show better picture but still figures are less than half of the beneficiaries received the financial assistance. This type of situation in long run increases disappointment among people and the motivation for institutional delivery created through financial help may reduce. Increased knowledge and awareness may help people to think more on mother and child health during delivery and change the behaviour but as government introduced the scheme to reduce the financial burden from the rural poor, without timely receive of financial help the spurt may subside.

Table 8 clearly shows that trends on receiving financial benefits are the same across the EAG states. States where overall receiving is low or the states where it is high, socio-economic and demographic factors have influenced without any administrative or geographical barriers on beneficiaries. As expected urban people, Hindus and women with one child are the highest on receiving the financial benefits. Higher ANC visits have increased proportion on receiving financial help from JSY. It clearly shows that awareness on JSY and its benefits increases with increased ANC. Though lowest percentage of people with higher education in states like Bihar, Madhya Pradesh, Chhattisgarh, Jharkhand have received the JSY financial benefits. Does this only due to non-acceptance of the amount or the low awareness, or they also belong to richer section? This needs to examine in detail further. Motivation by ASHA again shows a great result and people who had institutional delivery motivated by these community health workers call ASHA are always on the higher side to received the financial benefits. In Madhya Pradesh and Odisha, more the $50 \%$ of beneficiary received the JSY financial benefits with help of ASHA.

Results show that motivation by ASHA on institutional delivery has highly significant positive effect. This is call for further analysis to understand whether it reaches to all section of the society or only to a certain section. Table 9 shows that rural areas are the main working place for ASHAs as they are mainly appointed to motivate rural population on institutional delivery. ASHA workers are motivated mainly Hindus and non Hindus are left out on many states; this may create certain issues in future. It is perceived that ASHA workers reached to the expected sections on the state ethnic people and also across the states to illiterate and people with low level of education. Even people with higher parity who are in higher risk during delivery are also highly motivated by ASHA on institutional delivery. Though people who have had higher ANC did not agreed that ASHA had motivated them on institutional delivery, but that may shows that they were aware of institutional delivery through counselling by ANM or doctors during ANC. This shows clearly the importance of ASHA in a community to motivate and shape the goal of the NRHM's JSY program.

Though motivation by ASHA on institutional delivery is 
Table 5: Prevalence of institutional delivery by selected background characteristics in EAG states of India

\begin{tabular}{|c|c|c|c|c|c|c|c|c|c|c|c|c|c|c|c|c|}
\hline \multirow{2}{*}{$\begin{array}{l}\text { Background } \\
\text { characteristics }\end{array}$} & \multicolumn{8}{|c|}{ DLHS-2 } & \multicolumn{8}{|c|}{ DLHS-3 } \\
\hline & BH & $\mathrm{CH}$ & JH & MP & OD & RJ & UK & UP & BH & $\mathrm{CH}$ & JH & MP & OD & RJ & UK & UP \\
\hline \multicolumn{17}{|l|}{ Residence } \\
\hline Rural & 15.8 & 10.0 & 10.1 & 17.0 & 25.1 & 22.5 & 17.5 & 16.0 & 25.7 & 13.3 & 13.4 & 40.7 & 40.3 & 40.7 & 25.0 & 22.1 \\
\hline Urban & 45.8 & 50.4 & 60.5 & 60.2 & 62.7 & 56.5 & 42.2 & 41.5 & 54.4 & 47.9 & 59.3 & 72.4 & 74.1 & 67.6 & 59.3 & 38.6 \\
\hline \multicolumn{17}{|l|}{ Religion } \\
\hline Hindu & 19.5 & 16.6 & 20.4 & 25.8 & 30.7 & 30.0 & 24.9 & 21.1 & 31.9 & 20.1 & 23.7 & 48.6 & 46.6 & 47.9 & 31.3 & 26.5 \\
\hline Non-Hindu & 14.6 & 53.8 & 15.7 & 50.6 & 29.7 & 36.1 & 20.7 & 20.1 & 21.3 & 41.1 & 18.2 & 69.7 & 39.4 & 50.8 & 36.1 & 25.3 \\
\hline \multicolumn{17}{|l|}{ Ethnicity } \\
\hline Non $\mathrm{SC} / \mathrm{ST} / \mathrm{OBC}$ & 32.3 & 55.1 & 50.6 & 48.3 & 49.2 & 45.4 & 28.4 & 33.6 & 46.0 & 54.3 & 52.8 & 68.5 & 67.6 & 63.9 & 33.5 & 40.2 \\
\hline Scheduled Caste & 11.8 & 14.3 & 13.7 & 21.2 & 25.2 & 23.7 & 15.9 & 13.7 & 22.3 & 22.3 & 16.4 & 51.2 & 43.2 & 40.9 & 23.1 & 18.2 \\
\hline Scheduled Tribe & 12.6 & 9.7 & 7.1 & 10.4 & 13.6 & 22.2 & 22.9 & 11.5 & 17.2 & 11.4 & 8.8 & 29.3 & 21.6 & 40.2 & 32.0 & 15.2 \\
\hline Other castes & 17.3 & 16.4 & 21.0 & 29.0 & 37.6 & 28.4 & 20.2 & 18.8 & 29.3 & 23.0 & 23.3 & 54.3 & 54.7 & 47.3 & 36.8 & 24.1 \\
\hline \multicolumn{17}{|c|}{ Educational level (Years of Schooling) } \\
\hline Illiterate/ & 11.4 & 8.8 & 8.1 & 15.7 & 16.5 & 19.9 & 10.8 & 12.5 & 20.5 & 9.1 & 8.9 & 36.5 & 22.0 & 36.7 & 15.8 & 16.5 \\
\hline $0-5$ & 22.5 & 9.7 & 18.9 & 27.8 & 28.2 & 34.7 & 17.8 & 22.1 & 30.9 & 17.8 & 19.8 & 50.0 & 42.6 & 49.7 & 19.1 & 24.8 \\
\hline $6-10$ & 36.3 & 28.5 & 40.0 & 44.2 & 51.3 & 56.0 & 25.1 & 36.0 & 52.1 & 29.0 & 38.9 & 63.8 & 63.8 & 68.0 & 32.1 & 39.3 \\
\hline $11+$ & 68.2 & 72.9 & 80.7 & 80.4 & 76.3 & 83.1 & 64.2 & 69.3 & 76.6 & 69.1 & 76.1 & 87.2 & 88.5 & 88.8 & 62.8 & 69.1 \\
\hline \multicolumn{17}{|l|}{ Type of houst } \\
\hline Kuchcha & 10.7 & 9.9 & 8.0 & 15.0 & 21.9 & 17.6 & 12.9 & 10.5 & 20.3 & 13.7 & 11.5 & 38.9 & 34.2 & 34.6 & 19.7 & 16.7 \\
\hline Semi-pucca & 23.0 & 19.2 & 26.3 & 30.6 & 37.5 & 22.2 & 14.2 & 18.2 & 30.5 & 27.7 & 32.3 & 56.6 & 55.5 & 44.0 & 23.6 & 23.0 \\
\hline Pucca & 41.6 & 57.6 & 57.9 & 60.6 & 59.2 & 41.6 & 40.3 & 47.0 & 56.9 & 59.0 & 58.5 & 74.8 & 76.3 & 61.1 & 40.2 & 44.9 \\
\hline \multicolumn{17}{|c|}{ Age of women (in Years) } \\
\hline $15-19$ & 21.0 & 20.5 & 17.4 & 26.0 & 27.9 & 34.6 & 23.8 & 20.2 & 39.4 & 23.4 & 24.2 & 60.4 & 48.5 & 56.3 & 36.2 & 27.5 \\
\hline $20-24$ & 21.5 & 16.1 & 22.6 & 28.4 & 32.1 & 33.6 & 23.7 & 23.6 & 36.5 & 21.4 & 24.1 & 55.4 & 52 & 53.4 & 33.8 & 29.8 \\
\hline $25-29$ & 19.2 & 20.0 & 21.6 & 29.9 & 32.8 & 30.2 & 28.4 & 22.6 & 29.0 & 21 & 21.6 & 47.1 & 48 & 48.3 & 32.5 & 27.5 \\
\hline $30-34$ & 14.5 & 18.0 & 15.8 & 25.4 & 27.3 & 26.2 & 21.4 & 18.0 & 22.1 & 22.5 & 15.8 & 46.2 & 39 & 40.5 & 30.0 & 22.5 \\
\hline $35+$ & 13.0 & 15.2 & 11.9 & 21.7 & 24.4 & 21.1 & 15.8 & 14.3 & 18.5 & 13.1 & 9.8 & 35.0 & 28.7 & 33.1 & 24.3 & 18.1 \\
\hline \multicolumn{17}{|c|}{ Age at marriage (in Years) } \\
\hline$<18$ & 14.2 & 9.8 & 12.4 & 19.4 & 19.9 & 22.0 & 12.1 & 14.4 & 25.2 & 11.4 & 15.4 & 40.4 & 30.1 & 41.5 & 18.3 & 18.7 \\
\hline$>18$ & 32.4 & 29.3 & 35.6 & 43.7 & 42.7 & 44.7 & 30.3 & 33.4 & 43.7 & 30.5 & 25.9 & 62.8 & 55.2 & 57.8 & 36.1 & 38.3 \\
\hline \multicolumn{17}{|l|}{ Children } \\
\hline 1 & 30.8 & 29.2 & 34.3 & 42.7 & 50.1 & 46.9 & 37.3 & 35.8 & 47.5 & 35.8 & 33.8 & 68.5 & 67.5 & 62.0 & 47.8 & 42.8 \\
\hline 2 & 22.6 & 23.1 & 25.2 & 31.4 & 30.5 & 35.1 & 27.6 & 25.2 & 35.4 & 22.8 & 24.7 & 53.1 & 48.3 & 50.5 & 34.2 & 31.3 \\
\hline 3 & 17.2 & 10.2 & 14.6 & 24.0 & 22.1 & 25.7 & 20.2 & 19.2 & 25.0 & 13.2 & 13.7 & 40.7 & 29.1 & 41.0 & 19.4 & 22.1 \\
\hline $4+$ & 11.2 & 8.8 & 8.0 & 16.5 & 16.0 & 17.4 & 12.2 & 12.6 & 17.0 & 6.2 & 7.0 & 30.2 & 13.4 & 30.7 & 16.1 & 14.1 \\
\hline \multicolumn{17}{|l|}{ Pregnancy wastage } \\
\hline No & 18.1 & 17.6 & 19.1 & 27.0 & 29.5 & 29.8 & 24.1 & 20.3 & 29.8 & 20.0 & 19.7 & 49.1 & 45.6 & 47.7 & 31.7 & 25.5 \\
\hline Yes & 22.0 & 21.3 & 21.9 & 33.8 & 37.2 & 35.7 & 26.4 & 23.7 & 32.0 & 28.6 & 24.9 & 57.4 & 49.3 & 53.2 & 33.2 & 28.8 \\
\hline \multicolumn{17}{|l|}{ No. of ANC visits } \\
\hline No ANC visits & 9.1 & 8.4 & 4.1 & 10.3 & 11.8 & 12.4 & 9.7 & 9.1 & 17.4 & 5. & 4.1 & 26.3 & 16.7 & 26.5 & 10.8 & 11.3 \\
\hline 1 & 24.2 & 9.3 & 12.2 & 21.4 & 18.3 & 29.1 & 19.4 & 20.3 & 34.0 & 9.7 & 14.7 & 50.6 & 35.7 & 54.2 & 29.3 & 23.5 \\
\hline 2 & 28.9 & 10.1 & 22.4 & 23.9 & 25.3 & 30.7 & 20.5 & 22.5 & 29.4 & 13.4 & 17.8 & 55.0 & 34.1 & 51.5 & 33.9 & 28.5 \\
\hline 3 & 33.0 & 16.5 & 25.2 & 30.8 & 32.7 & 37.0 & 27.1 & 27.6 & 33.1 & 19.0 & 27.9 & 59.7 & 43.1 & 66.8 & 45.1 & 34.5 \\
\hline $4+$ & 58.9 & 35.8 & 59.7 & 59.2 & 54.2 & 57.3 & 63.6 & 55.8 & 71.4 & 43.3 & 56.7 & 78.4 & 70.3 & 79.3 & 66.8 & 63.5 \\
\hline \multicolumn{17}{|l|}{ Motivated by ASHA } \\
\hline No & NA & NA & NA & NA & NA & NA & NA & NA & 28.6 & 21.0 & 20.1 & 49.6 & 44.7 & 48.2 & 31.2 & 25.9 \\
\hline Yes & NA & NA & NA & NA & NA & NA & NA & NA & 61.7 & 21.9 & 45.8 & 67.3 & 64.9 & 49.7 & 51.0 & 50.7 \\
\hline All women & 18.7 & 17.9 & 19.5 & 27.7 & 30.6 & 30.7 & 24.3 & 20.9 & 30.1 & 21.1 & 20.2 & 50.0 & 46.2 & 48.2 & 31.9 & 26.2 \\
\hline Number of women & 18311 & 5361 & 7442 & 15926 & 9188 & 13509 & 3710 & 31005 & 21315 & 6114 & 11298 & 15839 & 7637 & 12405 & 4097 & 37563 \\
\hline
\end{tabular}

Source: computed from DLHS-2, 2002-04 and DLHS-3, 2007-08 data files.

Note: 1. BH: Bihar; CH: Chhattisgarh; JH: Jharkhand; MP: Madhya Pradesh; OD: Odisha; RJ: Rajasthan; UK: Uttarakhand; UP: Uttar Pradesh; NA: Not applicable. 2. Those currently married women in the age group of 15-44 years who experienced live or still births during three years preceding the survey. 3. The percentages are computed after applying survey sample weights and the number of women given in unweighted. 4. For some of the factors, the numbers in categories may not add up to total due to missing information.

important, but to make it happened in reality, role of transportation is also important. In rural areas mostly jeep/ car or tempo/auto was used to transport mothers to health facility for delivery across all EAG states (Table 10). Use of Ambulance is the lowest among all modes of transportation. Substantial number of people also reached at health facility to deliver by foot or by animal drawn cart. Providing financial assistance on transportation may not help people to avail the health facility to deliver where mode of transportation is not available enough. Providing ambulance may help them more instead of financial help on time.

\section{Conclusion}

There is substantial increase in institutional delivery in EAG states but there are wide variations among the states. The above discussion clearly pointed out that JSY have some impact on increasing institutional delivery in EAG states and especially in PHC, CHC/Rural hospital in some of the states. Similarly, education and standard of living played an important role on increase in institutional delivery and hence 


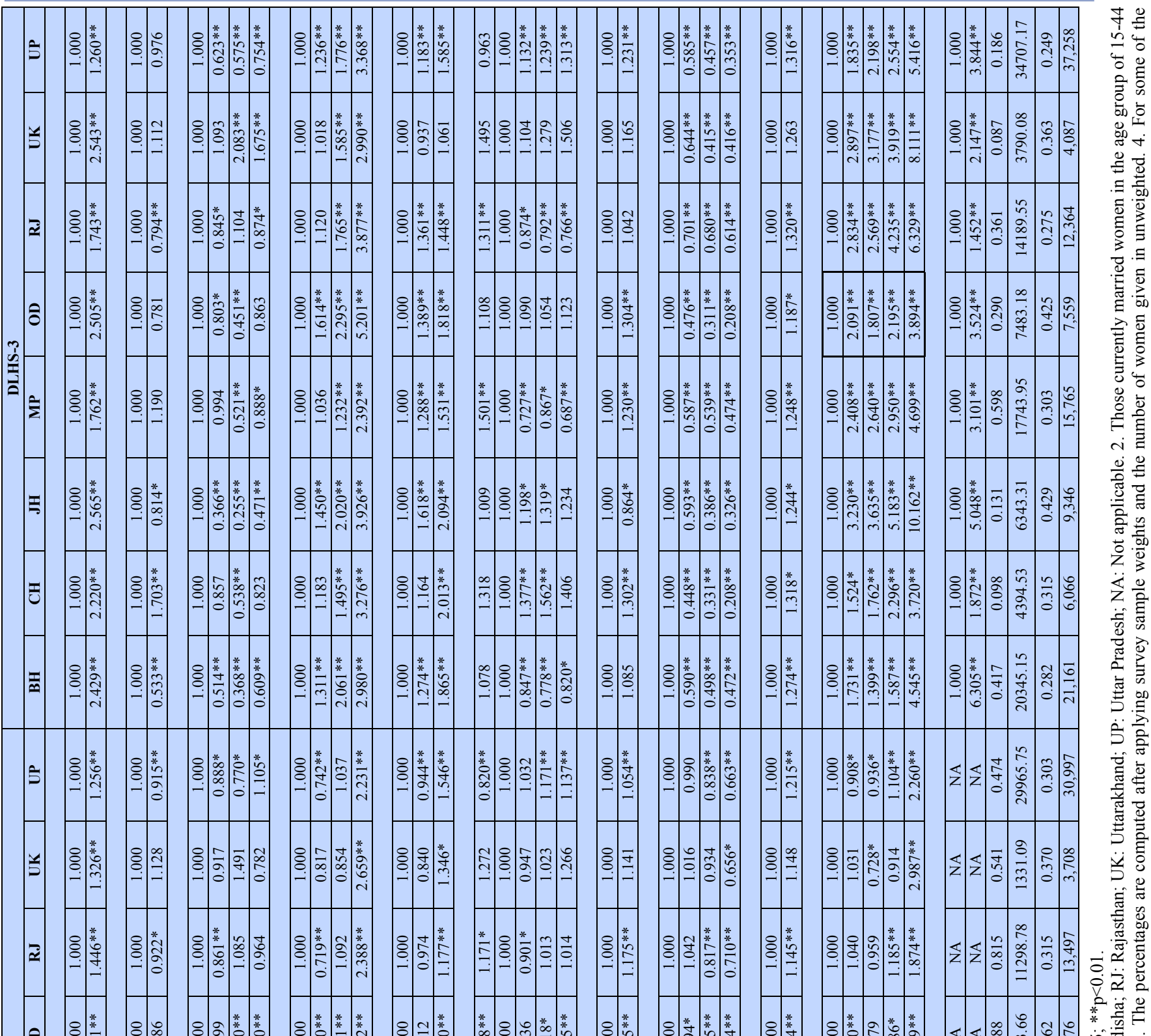

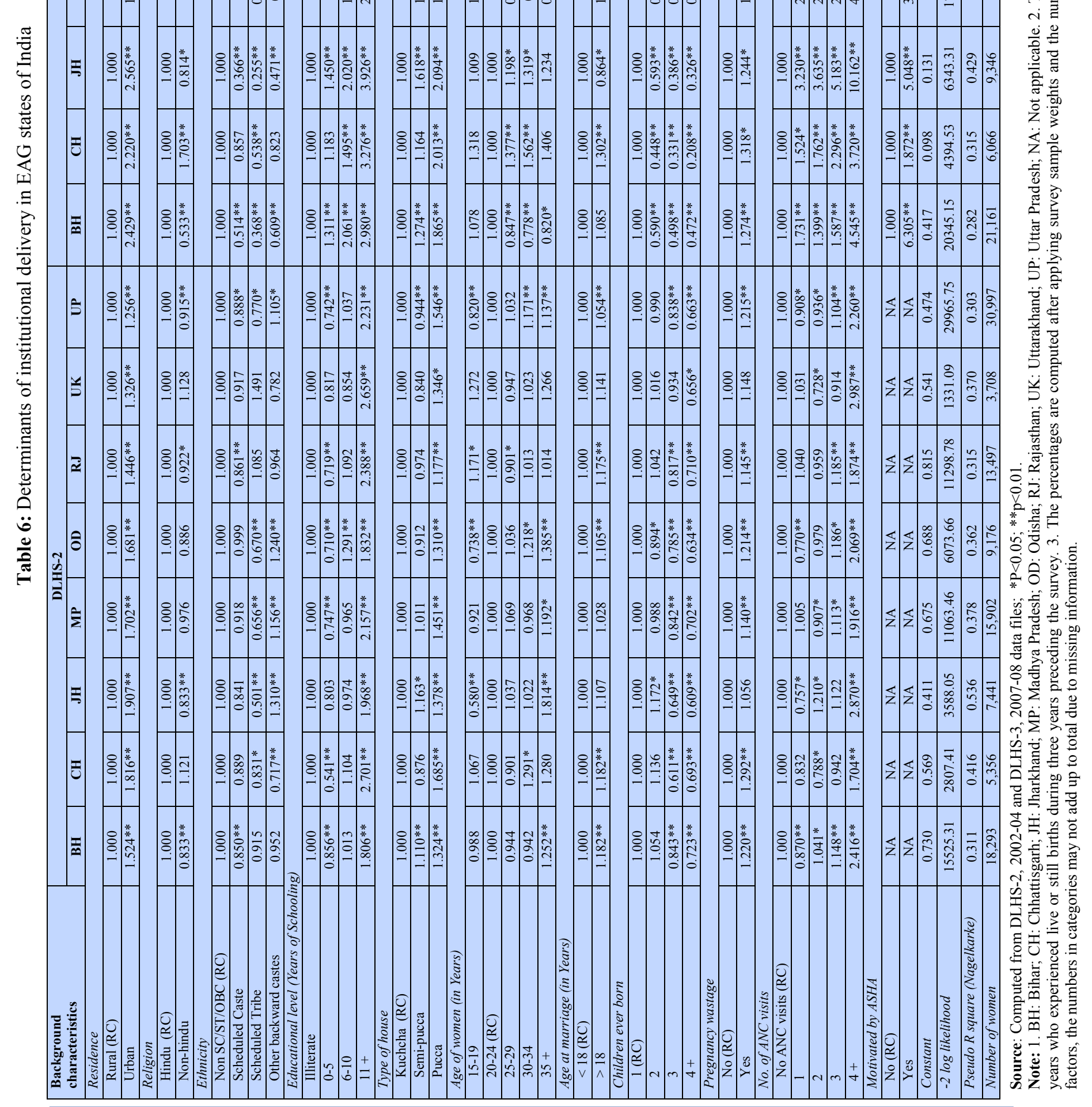

South East Asia Journal of Public Health 2013;3(2):4-18 
Table 7: Percentage of beneficiaries received financial benefits under JSY by types of delivery in EAG states of India

\begin{tabular}{|l|c|c|c|}
\hline States & $\begin{array}{c}\text { Among who had institutional } \\
\text { delivery }\end{array}$ & $\begin{array}{c}\text { Among who had home } \\
\text { delivery }\end{array}$ & All delivery \\
\hline Bihar & 20.3 & 1.2 & 6.9 \\
\hline Chhattisgarh & 19.1 & 3.6 & 6.8 \\
\hline Jharkhand & 5.7 & 1.5 & 2.3 \\
\hline Madhya Pradesh & 49.0 & 2.6 & 22.8 \\
\hline Odisha & 39.3 & 7.6 & 20.9 \\
\hline Rajasthan & 42.0 & 1.2 & 3.4 \\
\hline Uttarakhand & 9.6 & 1.2 & 7.5 \\
\hline Uttar Pradesh & 19.0 & 2.1 & 10.6 \\
\hline All EAG States & 28.0 & 1.9 & \\
\hline
\end{tabular}

Source: computed from DLHS-3, 2007-08 data files.

Table 8: Percentage of beneficiaries received financial benefits under JSY by selected background characteristics in EAG states of India

\begin{tabular}{|c|c|c|c|c|c|c|c|c|c|}
\hline $\begin{array}{l}\text { Background } \\
\text { characteristics }\end{array}$ & BH & $\mathbf{C H}$ & JH & MP & OD & RJ & UK & $\mathbf{U P}$ & $\begin{array}{c}\text { All EAG } \\
\text { States }\end{array}$ \\
\hline \multicolumn{10}{|l|}{ Residence } \\
\hline Rural & 6.5 & 7.0 & 2.5 & 24.7 & 23.1 & 19.8 & 7.6 & 3.5 & 10.1 \\
\hline Urban & 9.2 & 6.2 & 1.2 & 28.6 & 18.5 & 23.6 & 7.0 & 3.1 & 12.3 \\
\hline \multicolumn{10}{|l|}{ Religion } \\
\hline Hindu & 7.1 & 6.9 & 2.3 & 25.6 & 22.7 & 21.2 & 7.9 & 3.8 & 11.5 \\
\hline Non-Hindu & 6.4 & 6.4 & 2.0 & 29.4 & 14.7 & 18.5 & 4.2 & 2.0 & 6.4 \\
\hline \multicolumn{10}{|l|}{ Ethnicity } \\
\hline Non $\mathrm{SC} / \mathrm{ST} / \mathrm{OBC}$ & 6.7 & 5.2 & 2.0 & 22.6 & 22.4 & 21.0 & 7.0 & 3.4 & 10.1 \\
\hline Scheduled Caste & 6.8 & 8.1 & 2.5 & 31.5 & 26.1 & 20.1 & 8.7 & 4.0 & 11.5 \\
\hline Scheduled Tribe & 4.5 & 6.9 & 2.7 & 22.1 & 17.5 & 23.8 & 7.2 & 4.6 & 13.4 \\
\hline Other backward castes & 7.1 & 6.9 & 2.1 & 27.2 & 24.3 & 20.2 & 7.4 & 3.1 & 9.7 \\
\hline \multicolumn{10}{|c|}{ Educational level (Years of Schooling) } \\
\hline Illiterate/ No schooling & 6.5 & 5.6 & 2.0 & 23.7 & 16.5 & 18.1 & 4.5 & 2.9 & 8.7 \\
\hline $0-5$ & 8.6 & 8.0 & 3.0 & 29.2 & 26.1 & 22.6 & 5.1 & 3.1 & 13.0 \\
\hline $6-10$ & 8.3 & 9.2 & 3.1 & 30.4 & 28.2 & 26.8 & 8.0 & 4.6 & 14.1 \\
\hline $11+$ & 3.5 & 3.3 & 1.8 & 19.1 & 19.8 & 25.4 & 12.4 & 4.9 & 10.8 \\
\hline \multicolumn{10}{|l|}{ Type of house } \\
\hline Kuchcha & 6.2 & 7.1 & 2.3 & 25.8 & 21.7 & 19.3 & 6.6 & 3.7 & 11.2 \\
\hline Semi-pucca & 7.8 & 7.6 & 3.0 & 28.9 & 25.8 & 20.0 & 8.2 & 3.1 & 9.3 \\
\hline Pucca & 6.8 & 4.4 & 1.8 & 22.9 & 20.4 & 22.6 & 7.4 & 3.5 & 11.4 \\
\hline \multicolumn{10}{|l|}{ Children ever born } \\
\hline 1 & 9.0 & 11.6 & 3.6 & 32.6 & 29.4 & 26.6 & 10.0 & 4.7 & 15.2 \\
\hline 2 & 6.5 & 5.8 & 2.4 & 26.9 & 24.1 & 20.6 & 8.3 & 4.1 & 12.1 \\
\hline 3 & 6.4 & 5.3 & 1.8 & 22.5 & 16.7 & 18.5 & 5.3 & 2.9 & 8.8 \\
\hline $4+$ & 6.2 & 3.0 & 1.6 & 19.0 & 9.0 & 14.8 & 4.3 & 2.4 & 6.1 \\
\hline \multicolumn{10}{|l|}{ No of ANC visits } \\
\hline No ANC visits & 4.2 & 3.0 & 1.0 & 15.9 & 10.9 & 11.0 & 3.7 & 1.8 & 5.8 \\
\hline 1 & 9.0 & 5.4 & 3.9 & 30.0 & 25.4 & 26.6 & 12.1 & 3.0 & 12.8 \\
\hline 2 & 10.3 & 7.7 & 3.9 & 32.8 & 22.4 & 25.5 & 9.1 & 4.3 & 11.4 \\
\hline 3 & 7.9 & 7.9 & 3.1 & 34.1 & 24.0 & 29.8 & 11.6 & 4.1 & 13.7 \\
\hline $4+$ & 6.5 & 8.3 & 2.9 & 28.4 & 25.6 & 29.6 & 9.9 & 4.8 & 15.9 \\
\hline \multicolumn{10}{|l|}{ Motivated by ASHA } \\
\hline No & 5.4 & 6.3 & 2.3 & 25.2 & 19.9 & 20.7 & 6.5 & 3.1 & 9.9 \\
\hline Yes & 37.4 & 14.0 & 10.4 & 55.9 & 51.6 & 30.0 & 31.6 & 29.0 & 36.7 \\
\hline All women & 6.9 & 6.8 & 2.3 & 25.8 & 22.3 & 20.9 & 7.5 & 3.4 & 10.6 \\
\hline
\end{tabular}

Source: computed from DLHS-3, 2007-08 data files.

Note: 1. BH: Bihar; CH: Chhattisgarh; JH: Jharkhand; MP: Madhya Pradesh; OD: Odisha; RJ: Rajasthan; UK: Uttarakhand; UP: Uttar Pradesh. 2. Those currently married women in the age group of 15-44 years who experienced live or still births during three years preceding the survey. 3. The percentages are computed after applying survey sample weights and the number of women given in unweighted. 4. For some of the factors, the numbers in categories may not add up to total due to missing information. 
Table 9: Percentage of women motivated by ASHA for institutional delivery by selected background characteristics among who had institutional delivery in EAG states of India

\begin{tabular}{|c|c|c|c|c|c|c|c|c|c|}
\hline $\begin{array}{l}\text { Background } \\
\text { characteristics }\end{array}$ & BH & CH & JH & MP & OD & RJ & UK & UP & $\begin{array}{c}\text { All EAG } \\
\text { States }\end{array}$ \\
\hline \multicolumn{10}{|l|}{ Residence } \\
\hline Rural & 12.4 & 13.3 & 0.8 & 4.8 & 14.7 & 3.2 & 8.0 & 3.1 & 6.6 \\
\hline Urban & 2.2 & 1.3 & 0.3 & 0.4 & 0.9 & 0.6 & 2.2 & 0.5 & 0.8 \\
\hline \multicolumn{10}{|l|}{ Religion } \\
\hline Hindu & 9.5 & 7.4 & 0.4 & 3.1 & 11.0 & 2.3 & 6.3 & 2.6 & 4.8 \\
\hline Non-Hindu & 9.9 & 3.6 & 1.5 & 1.2 & 7.9 & 1.3 & 3.3 & 0.8 & 2.6 \\
\hline \multicolumn{10}{|l|}{ Ethnicity } \\
\hline Non SC/ST/OBC & 5.0 & 1.9 & 0.2 & 1.6 & 7.6 & 1.0 & 6.4 & 1.4 & 2.8 \\
\hline Scheduled Caste & 15.1 & 5.6 & 0.9 & 2.4 & 12.5 & 3.5 & 8.5 & 4.5 & 6.5 \\
\hline Scheduled Tribe & 3.3 & 14.7 & 1.5 & 7.4 & 17.6 & 3.2 & 6.1 & 4.2 & 7.6 \\
\hline Other castes & 10.0 & 6.5 & 0.5 & 2.4 & 10.8 & 2.1 & 2.0 & 2.1 & 4.2 \\
\hline \multicolumn{10}{|c|}{ Educational level (Years of Schooling) } \\
\hline Illiterate & 14.1 & 13.7 & 0.9 & 3.4 & 17.5 & 3.0 & 5.2 & 3.4 & 6.1 \\
\hline $0-5$ & 12.2 & 7.8 & 1.2 & 4.0 & 12.3 & 2.3 & 6.9 & 2.5 & 5.5 \\
\hline $6-10$ & 5.5 & 7.2 & 0.4 & 2.9 & 10.4 & 1.7 & 6.3 & 1.4 & 3.8 \\
\hline $11+$ & 1.0 & 1.7 & 0.4 & 0.6 & 4.6 & 0.3 & 5.4 & 1.0 & 1.5 \\
\hline \multicolumn{10}{|l|}{ Type of house } \\
\hline Kuchcha & 14.1 & 12.6 & 1.0 & 4.7 & 14.1 & 4.2 & 5.0 & 5.2 & 7.4 \\
\hline Semi-pucca & 10.6 & 4.4 & 0.0 & 2.4 & 9.8 & 2.5 & 8.2 & 2.1 & 4.6 \\
\hline Pucca & 3.6 & 0.6 & 0.5 & 0.7 & 6.8 & 1.2 & 5.4 & 0.8 & 1.9 \\
\hline \multicolumn{10}{|l|}{ Children ever born } \\
\hline 1 & 7.3 & 5.6 & 0.7 & 2.6 & 8.5 & 2.1 & 5.6 & 2.1 & 3.9 \\
\hline 2 & 6.5 & 6.3 & 0.4 & 2.7 & 11.6 & 2.3 & 6.0 & 1.9 & 4.0 \\
\hline 3 & 11.8 & 9.7 & 0.9 & 3.4 & 15.9 & 2.1 & 7.0 & 2.5 & 5.2 \\
\hline $4+$ & 16.0 & 14.1 & 0.6 & 3.7 & 14.4 & 2.6 & 3.0 & 2.5 & 6.0 \\
\hline \multicolumn{10}{|l|}{ No. of ANC visits } \\
\hline No ANC visits & 9.0 & 11.1 & 0.6 & 3.1 & 8.5 & 2.6 & 3.7 & 1.7 & 4.1 \\
\hline 1 & 11.2 & 11.4 & 4.0 & 5.3 & 13.0 & 2.5 & 18.4 & 1.5 & 5.8 \\
\hline 2 & 16.7 & 12.9 & 0.8 & 3.9 & 16.0 & 2.6 & 10.1 & 3.2 & 6.3 \\
\hline 3 & 9.5 & 9.9 & 0.4 & 3.3 & 12.3 & 2.7 & 4.8 & 1.9 & 4.7 \\
\hline $4+$ & 2.7 & 3.9 & 0.4 & 1.4 & 8.9 & 1.2 & 4.1 & 1.2 & 2.8 \\
\hline All women & 9.6 & 7.1 & 0.6 & 2.9 & 10.9 & 2.2 & 5.9 & 2.2 & 4.5 \\
\hline
\end{tabular}

Source: computed from DLHS-3, 2007-08 data files.

Note: 1. BH: Bihar; CH: Chhattisgarh; JH: Jharkhand; MP: Madhya Pradesh; OD: Odisha; RJ: Rajasthan; UK: Uttarakhand; UP: Uttar Pradesh. 2. Those currently married women in the age group of 15-44 years who experienced live or still births during three years preceding the survey. 3. The percentages are computed after applying survey sample weights and the number of women given in unweighted. 4. For some of the factors, the numbers in categories may not add up to total due to missing information.

Table 10: Percentage of women used different mode of transport to have institutional delivery in EAG states of India

\begin{tabular}{|l|c|c|c|c|c|c|c|c|c|}
\hline Mode of Transport & BH & $\mathbf{C H}$ & $\mathbf{J H}$ & $\mathbf{M P}$ & OD & RJ & UK & UP & $\begin{array}{c}\text { All EAG } \\
\text { States }\end{array}$ \\
\hline Ambulance & 1.7 & 3.1 & 2.2 & 2.2 & 3.3 & 0.6 & 2.4 & 0.5 & 1.6 \\
\hline Jeep/Car & 25.6 & 45.3 & 38.3 & 29.6 & 40.3 & 54.9 & 56.1 & 32.7 & 36.7 \\
\hline Motor cycle/Scooter & 4.5 & 11.5 & 9.4 & 16.1 & 4.7 & 9.4 & 9.1 & 11.5 & 10.3 \\
\hline Bus/Train & 4.5 & 4.6 & 3.8 & 9.2 & 1.7 & 2.7 & 4.3 & 3.9 & 4.8 \\
\hline Tempo/Auto/Tractor & 39.1 & 19.9 & 32.9 & 27.4 & 37.6 & 24.0 & 12.4 & 23.5 & 28.1 \\
\hline Animal drawn cart & 7.0 & 0.7 & 3.5 & 2.6 & 0.2 & 1.2 & 4.6 & 5.8 & 3.7 \\
\hline Foot march & 9.4 & 5.8 & 3.1 & 8.8 & 2.4 & 5.7 & 8.5 & 6.5 & 6.8 \\
\hline Other & 8.3 & 9.1 & 6.9 & 4.2 & 9.8 & 1.6 & 2.6 & 15.4 & 8.1 \\
\hline Total & 100.0 & 100.0 & 100.0 & 100.0 & 100.0 & 100.0 & 100.0 & 100.0 & 100.0 \\
\hline Number of women & 5,906 & 1,100 & 2,006 & 7,450 & 3,369 & 5,642 & 1,232 & 9,248 & 35,953 \\
\hline
\end{tabular}

Source: computed from DLHS-3, 2007-08 data files.

Note: 1. BH: Bihar; CH: Chhattisgarh; JH: Jharkhand; MP: Madhya Pradesh; OD: Odisha; RJ: Rajasthan; UK: Uttarakhand; UP: Uttar Pradesh. 2. Those currently married women in the age group of 15-44 years who experienced live or still births during three years preceding the survey. 
the benefits of the JSY scheme but states like Madhya Pradesh, Rajasthan and Odisha where massive rise in institutional delivery has been observed, these factors failed to explain the totality. Motivation by ASHA for institutional delivery came out as an important factor in the study.

The study thus concludes that the JSY undoubtedly contributed to a substantial improvement in institutional delivery and increased pressure on the public health system especially in $\mathrm{PHC}, \mathrm{CHC} /$ rural hospitals. Institutional delivery needs to be backed by good quality of both basic Emergency Obstetric Care (EmOC) and comprehensive emergency obstetric care. Most of the EAG states are not fully equipped with EmOC services. Even sometime lack of skilled human resource makes $\mathrm{C}$-section unavailable in rural setups. Transport for referral is also a burning side of accessing/utilizing institutional delivery. Moreover, micro birth plan and birth preparedness are rare in rural India. ASHA workers may provide support to mothers on these with more hands on training.

It was obvious that each state in India has unique characteristics even if we try to bring them under one umbrella for programme point of view. The present study came out with vivid description how each state responded differently on the same JSY scheme. Health is under state and centrally sponsor scheme like JSY need special attention from state on implementation. The utilisation of the scheme differs across the EAG states and its impact on institutional delivery. Even the receiving financial benefits under the JSY also vary across the states. Moreover, people with different socio -economic groups in these states responded differently on institutional delivery after implementation of JSY.

The scheme was aimed to bring the marginalized and poorer section of the community to forefront and provide them the maternal health care through promoting institutional delivery. But women belong to $\mathrm{SC} / \mathrm{ST} / \mathrm{OBC}$ community are still not availing the services in these states. This depicts that the scheme still not reached to a particular section of the society for which it meant for. The scheme offered safe delivery/ institutional delivery or BPL households and the study shows that the JSY provided support to them. Madhya Pradesh, Odisha, and Rajasthan have an impressive rise in institutional delivery and also high percentage of women received financial benefits through the JSY. This should use as a model case and promote in other states like Jharkhand and Chhattisgarh where acceptance is low. Role of ASHA is very important in this entire program. A person from community obviously influenced people more than any other channel of media.

The paper clearly shows that ASHA workers are the champions of the entire program to reach to this high level of success. Many other progamatic factors influence in success of a scheme in certain states and further research may focus on more of programmatic factors to understand the difference in utilization of the
JSY scheme in EAG states. Planned implementation of programme through NRHM may help achieve the goals of NPP 2000 and hence MDG-5.

\section{References}

1. World Health Organization. The World Health Report 2003: Shaping the future. Geneva: World Health Organization, 2003.

2. India, Registrar General. Special Bulletin on Maternal Mortality in India 2007-09, Sample Registration System. New Delhi: Ministry of Home Affair, 2011.

3. International Institute for Population Sciences (IIPS). District Level Households and Facility Survey (DLHS-3), 2007-08: Mumbai: IIPS, 2010 .

4. International Institute for Population Sciences (IIPS). District Level Household Survey Reproductive and Child Health, 2002-04, India. Mumbai: IIPS, 2006.

5. Ministry of Health and Family Welfare (MOHFW). National Population Policy 2000. New Delhi: Ministry of Health and Family Welfare, 2000.

6. Ministry of Health and Family Welfare (MOHFW). National Rural Health Mission (2005-2012), Mission Document, Government of India. New Delhi: Ministry of Health and Family Welfare, 2005.

7. Ministry of Health and Family Welfare. Janani Suraksha Yojana: features and frequently asked questions and answers. New Delhi: Maternal Health Division, Ministry of Health and Family Welfare, Government of India, 2006.

8. Ministry of Health and Family Welfare (MOHFW). Janani Suraksha Yojana: Guidelines for Implementation, Government of India. New Delhi: Ministry of Health and Family Welfare, 2005.

9. Lim SS, Dandona L, Hoisington JA, James SL, Hogan MC, Gakidou E. India's Janani Suraksha Yojana, a conditional cash transfer programme to increase births in health facilities: an impact evaluation. Lancet 2010; 375(9730):2009-23.

10. Kumari V, Dhawan D, Singh AR. Advantages as perceived by the beneficiaries of Janani Suraksha Yojana (JSY) in Bikaner district. $J$ Dairying Foods Home Sci 2009; 28 (3 \& 4): 247-9.

11. Mehta P, Shubhra D. A Study on Awareness about Janani Suraksha Yojana (JSY) among Rural Women. https://www.socialtext.net/.../ Report $\% 20$ of $\% 20$ study $\% 20$ on $\% 20 J S Y$.doc (accessed Dec 2013) 
12. Deoki N, Shobha M, Tripathy RM, Poonam K, Nair KS, Tekhre YL. A Rapid Appraisal on Functioning of Janani Suraksha Yojana in South Orissa. New Delhi: National Institute of Health and Family Welfare, 2008.

13. International Institute for Population Sciences and Macro International. National Family Health Survey (NFHS-3), 2005-06: India: Volume 1, Mumbai: IIPS, 2007.

14. International Institute for Population Sciences and ORC Macro. National Family Health Survey (NFHS-2), 1998-99: India, Mumbai: IIPS, 2000.

15. International Institute for Population Sciences National Family Health Survey (NFHS-1), 199293: India, Mumbai: IIPS.1995.

16. International Institute for Population Sciences. Rapid Household Survey - Reproductive and Child Health (RHS-RCH-1\&2), 1998-99, India, Mumbai: IIPS, 2001.

17. Retherford RD, Choe MK. Statistical Model for Causal Analysis. New York: John Wiley and Sons, INC, 1993.

18. Kesterton AJ, Cleland J, Sloggett A, Ronsmans C. Institutional delivery in rural India: the relative importance of accessibility and economic status. BMC Pregnancy Childbirth 2010;10:30.

19. Paul L, Chellan R. Delivery Care for Scheduled Tribe Women in India: A Disaggregated Regional Analysis. Artha Vijnana 2009:LI(3): 297-314.
20. Gupta SK, Pal DK, Tiwari R, Garg R, Shrivastava AK, Sarawagi R, Patil R, Agarwal L, Gupta P, Lahariya C. Impact of Janani Suraksha Yojana on institutional delivery rate and maternal morbidity and mortality: an observational study in India. J Health Popul Nutr 2012; 30(4):464-71.

21. Sharma MP, Soni SC, Bhattacharya M, Datta U, Gupta S, Nandan D. An assessment of institutional deliveries under JSY at different levels of health care in Jaipur District, Rajasthan. Indian J Public Health 2009;53:17782.

22. Sugathan K, Mishra V, Retherford R. Promoting Institutional Deliveries in Rural India: The Role of Antenatal-Care Services. Mumbai, India: International Institute for Population Sciences, and Honolulu: East-West Center, Population and Health Studies, USA, 2001.

23. Panja TK, Mukhopadhyay DK, Sinha N, Saren AB, Sinhababu A, Biswas AB. Are institutional deliveries promoted by Janani Suraksha Yojana in a district of West Bengal, India? Indian $J$ Public Health 2012;56(1);69-72.

24. United Nations Population Fund (UNFPA). Concurrent Assessment of Janani Suraksha Yojana (JSY) in Selected States: Bihar, Madhya Pradesh, Orissa, Rajasthan, Uttar Pradesh. UNFPA: New Delhi, 2009. 